\title{
Evaluation of short-period rainfall estimates from Kalpana-1 satellite using MET software
}

\author{
Soma Sen Roy ${ }^{1, *}$, Subhendu Brata Saha ${ }^{1}$, Hashmi Fatima $^{1}$, \\ S K RoY BHowmik ${ }^{1}$ and $\mathrm{P}$ K Kundu ${ }^{2}$ \\ ${ }^{1}$ India Meteorological Department, Lodi Road, New Delhi 110 003, India. \\ ${ }^{2}$ Department of Mathematics, Jadavpur University, Kolkata 700 032, India. \\ *Corresponding author.e-mail: somasenroy@yahoo.com
}

The INSAT Multispectral Rainfall Algorithm (IMSRA) technique for rainfall estimation, has recently been developed to meet the shortcomings of the Global Precipitation Index (GPI) technique of rainfall estimation from the data of geostationary satellites; especially for accurate short period rainfall estimates. This study evaluates the 3-hourly precipitation estimates by this technique as well as the rainfall estimates by the GPI technique using data of the Kalpana-1 satellite, over the Indian region for the south-west monsoon season of 2010 to understand their relative strengths and weaknesses in estimating short period rainfall. The gridded 3 hourly accumulated TRMM satellite (3B42 V6 product or TMPA product) and surface raingauge data for stations over the Indian region for the same period is used as the standard measure of rainfall estimates. The Method for Object-based Diagnostic Evaluation (MODE) utility of the METv3.0 software, has been used for the evaluation purpose. The results show that the new IMSRA technique is closer to the TMPA rainfall estimate, in terms of areal spread, geometric shape and location of rainfall areas, as compared to the GPI technique. The overlap of matching rainfall areas with respect to TMPA rainfall patches is also higher for the IMSRA estimates as compared to the GPI values. However, both satellite rainfall estimates are observed to be generally higher compared to the TMPA measurements. However, the values for the highest $10 \%$ of the rainfall rates in any rainfall patch, is generally higher for rainfall measured by the IMSRA technique, as compared to the estimates by the GPI technique. This may partly be due to the capping maximum limit of $3 \mathrm{~mm} / \mathrm{hr}$ for rainfall measured by the GPI technique limits the total 3-hour accumulation to $9 \mathrm{~mm}$ even during heavy rainfall episodes. This is not so with IMSRA technique, which has no such limiting value. However, this general overestimation of the rainfall amount, measured by both techniques, and the greater error in case of IMSRA estimates, is also validated independently with respect to surface raingauge observations. Hence the observed overestimation by the IMSRA technique for the highest 10th percentile rainfall rates in rainfall episodes, is real. This overestimation by the latter technique may become a significant source of error, if the IMSRA estimate is used for monitoring very heavy rainfall episodes. In all other respects, since the IMSRA method shows significant improvement over the GPI, the rainfall estimates by the IMSRA method may be used for operational short period rainfall estimation.

Keywords. Satellite derived Global Precipitation Index rainfall; INSAT Multispectral Rainfall Algorithm; meteorological evaluation tools; MODE. 


\section{Introduction}

Precipitation is an essential component of the hydrological cycle and accurate global rainfall coverage is necessary to improve short-term, medium and long-term weather forecasts and climate prediction. There is need for accurate and uniform retrieval of precipitation on time and space scales consistent with the nature and development of precipitating clouds, i.e., a few hours and a few kilometers for high impact rainfall events to synoptic scale systems, which evolve over many days and provide widespread rainfall. Raingauge networks, though most accurate, are limited to over the land, and are non-uniformly distributed. Advanced dense radar networks are also limited to very few countries. Hence, rainfall data, with a high spatial and temporal resolution and uniform over wide regions, is mostly available from satellite data. Continuous data over a large area between $60^{\circ} \mathrm{S}$ and $60^{\circ} \mathrm{N}$ is available only from instruments onboard geostationary platforms. This restriction currently limits available spectrum of electromagnetic wavelength to those in the infrared (IR) and visible (VIS) part of electromagnetic spectrum. The lack of visible data at night has generally restricted geostationary rainfall monitoring technique to the use of IR channel data alone. Though the satellite IR algorithms benefit from high temporal sampling, the IR radiances emanating from cloud tops have only an indirect relationship with surface rainfall which, in turn, results in a weak statistical relationship between rainfall and cloudiness.

Almost all IR techniques are based on variations of the premise that precipitation is most likely to be associated with deep clouds and thus with cold cloud tops, as observed by an infrared imager. The most commonly used statistical relationship between observed radiances and rainfall realized, was initially developed by Arkin (1979) for the domain of the GARP Atlantic Tropical Experiment. It estimates monthly rainfall accumulation in $2.5^{\circ} \times 2.5^{\circ}$ grid boxes, using a statistical relationship for the fractional area of the grid box, covered by the clouds with equivalent blackbody temperature below $235 \mathrm{~K}$ in infrared imagery. When this relationship (also called Global Precipitation Index (GPI)) was later applied to various regions and for data from different satellites, it was observed that the GPI estimates of rainfall are not without errors. For example, high-level cirrus and other non-precipitating clouds are often screened in as precipitating with this simple relationship. Besides, the capping limit of $3 \mathrm{~mm} / \mathrm{hr}$ rainfall rate implies that the heavy rainfall episodes (with rainfall rate greater than the capping limit of GPI) are underestimated by this technique. The relationship has been validated over different regions of the world and it has been found that as compared to raingauge reports, the Arkin's technique generally overestimates precipitation falling over land (Arkin and Ardanuy 1989), while over tropical oceans the bias is near zero (Xie and Arkin 1995). Over the Indian region, weekly GPI estimates of rainfall using INSAT-1B data were observed to be poorly correlated with the surface raingauge rainfall over the mountainous regions in north-east India and eastern peninsular India (Arkin et al. 1989). Additionally, Richards and Arkin (1981) also found that the correlations of the brightness temperature with the rainfall realized, decreased with increasing temporal or spatial resolution. More recent efforts at validating GPI rainfall from Kalpana-1 satellite over the Indian region have been with respect to its ability to replicate the diurnal, daily, monthly, seasonal and event-based accumulations of rainfall. The standard against which they are measured is the $1^{\circ}$ gridded rainfall data of IMD (Durai et al. 2010) or with respect to the rainfall data from the Global Precipitation Climatology Project and Global Precipitation Climatology Centre (Prakash et al. 2011). Both studies have found that although the estimate is useful for large spatial and temporal scales, due to the capping maximum value of $72 \mathrm{~mm} /$ day, the heavy rainfall episodes are generally underestimated by the GPI technique. This, combined with the general overestimation of lesser rainfall episodes, implies that when the total rainfall is accumulated over longer temporal and spatial scales, the errors average out. However, this has limited the use of this data to estimate large area rainfall for cases with short temporal and high spatial resolution. Nevertheless, the simplicity of the technique, and the small requirement of computer time, makes it the precipitation estimation technique of choice, for most satellite meteorology centres.

Most of the problems with estimation of rainfall from the IR channel of geostationary satellites, stems from the lack of information of the sub-cloud layer of air below the satellite. Low earth orbiting (LEO) satellites, with microwave sensitive payloads, provide less frequent information but more direct rainfall estimation than visible (VIS)/ infrared (IR) observations from geostationary satellites. The Tropical Rainfall Measuring Mission (TRMM) is the first LEO satellite mission of National Aeronautics and Space Administration (NASA), United States of America, launched in November 1997, dedicated to observing and understanding tropical precipitation and its relation with global climate. TRMM provides a unique platform for measuring rainfall from space using a passive sensor TRMM Microwave Imager (TMI; Kummerow et al. 1998), an active Precipitation Radar (PR) operating at $13.6 \mathrm{GHz}$, and a visible 
and infrared scanner (VIRS) radiometer. Attempts have been made to improve the precipitation estimation by geostationary satellites by incorporating the information from the TRMM satellites. Some such algorithms are described by Gairola and Krishnamurti (1992) and Todd et al. (2001). Over the Indian region, a new algorithm - IMSRA (INSAT Multispectral Rainfall Algorithm) has been developed at the Indian Space Research Organisation by Gairola et al. (2010) for the Kalpana-1 satellite, which has the potential of meeting this requirement of high spatial and temporal resolution rainfall. Unlike the Arkin's method, IMSRA is capable of providing rainfall estimates and its distributions in high spatial resolution $\left(0.25^{\circ} \times 0.25^{\circ}\right)$ and temporal resolution ( 3 hourly). The development of this algorithm included two major steps: (a) classification of rainbearing clouds using a cloud classification scheme of Roca et al. (2002) utilizing Kalpana-1 IR and water vapour (WV) brightness temperatures (Tb) and (b) collocation of Kalpana-1 IR brightness temperature with TRMM-PR surface rain rate and establishment of a regression relation between them.

Although both products - GPI and IMSRA, derived from the Kalpana-1 satellite, are available for real time applications, they have to be evaluated with respect to a standard dataset to test their relative utility for short-range precipitation estimation and forecasting. Earlier verification attempts of the IMSRA algorithm have provided qualitative comparisons with TRMM data, accumulated for daily or monthly values for the monsoon season (June-September) of 2008 and 2009 (Prakash et al. 2010). However, such validation of the precipitation estimates, with standard daily accumulation precipitation fields such as GPCP V2 (Adler et al. 2003) or APHRODITE (Yatagai et al. 2009) would average out many of the spatial and temporal non-uniformities of precipitation in the shortrange ( $\sim 3$ hours or less), that would be valuable for short-range forecasting. Validation using self recording raingauges and automatic weather stations, is particularly difficult at short time scales and over large regions. This is because of the non-uniform distribution of the raingauge network throughout the domain, which presents difficulties in delineating rainy areas, especially given the subscale variability of most rainfall events. In this context, radar observations of rainfall are generally more useful, though radar is itself a remote sensing technique with its own unique error sources and calibration problems. Also, this data is limited to few regions of the Indian domain. The most viable dataset with similar space-time scales of interest is the TRMM 3B42 V6 product. The TRMM $3 \mathrm{~B} 42 \mathrm{~V} 6$ is a 3 -hourly, $0.25^{\circ}$ product based on TRMM Multisatellite Precipitation Analysis (TMPA; Huffman et al. 2007). However, meaningful evaluation of the performance of an algorithm can be established only if the accuracy of the reference standard is known. As pointed out by Krajewski (1993), the observed differences between satellite-based estimates and a reference estimate can be attributed to errors in both compared sensors. Many studies have focused on the validation and inter-comparison of the TMPA products with raingauge data for various regions, e.g., Africa (Dinku et al. 2007; Li et al. 2008), Europe (Feidas 2010; Villarini 2010), south and southeast Asia (Islam and Uyeda 2005; Chokngamwong and Chiu 2007; Han et al. 2011), North and South America (Su et al. 2008; Han et al. 2011), and for the globe (Huffman et al. 2007). The results indicate that TMPA data match well with raingauge observations at all locations. TMPA is slightly underestimated for semi-arid regions and overestimated for humid regions. The relative magnitude of TMPA rain event accumulation compared to raingauge accumulation is noted to be smaller for urbanized watersheds and high intensity events. The correlation of TMPA accuracy with temperature and relative humidity and the analysis of accuracy by season indicate TMPA is more accurate for convective rainfall events (Chokngamwong and Chiu 2007; Han et al. 2011). Over the Indian region, studies by Rahman and Sengupta (2007) show that the TRMM 3B42 V6 (TMPA) performs better over the Indian region as compared to TRMM 3B42 V5, when compared to raingauge data. Another recent study of the validation of TMPA daily rainfall product for the Indian summer monsoon using the $1^{\circ}$ gridded rainfall product of IMD, shows that TMPA reasonably depicts the pattern and intensity of torrential rain from individual monsoon low-pressure systems and depressions (Rahman et al. 2009). This study also showed that the seasonal mean and intra-seasonal variability of TMPA rainfall estimates in the nonhill regions, are within about $15 \%$ of observations. Other studies show that the TMPA estimates over the Western Ghats are most accurate over regions of moderate rainfall and mainly inaccurate in regions of sharp rainfall gradient (Nair et al. 2009). In terms of the magnitude of the rainfall amounts, over the windward side of the Western Ghats the 3B42V6 product was unable to resolve the heavy orographic rainfall amounts and over the leeward side, the rainfall amounts in the immediate rain-shadow region were overestimated. Hence this dataset (TMPA) will be used as the standard, to which the precipitation estimate derived from the Kalpana-1 satellite by the two methods GPI and IMSRA will be compared qualitatively and quantitatively for the Indian region. To further 
validate the results of comparison with respect to the TMPA estimates, the precipitation estimates by the IMSRA and GPI technique are also compared to point estimates of rainfall from surface raingauge stations over the Indian region.

\section{Data and methodology used}

The precipitation estimate from the Kalpana-1 satellite, derived from two different algorithms GPI and IMSRA were obtained at 3 hourly intervals for the entire monsoon season of 2010 (1 June30 September, 2010). The domain was selected to be for the south Asian region, including the Indian subcontinent $\left(-40^{\circ}-40^{\circ} \mathrm{N}\right.$ and $\left.30^{\circ}-120^{\circ} \mathrm{E}\right)$. TMPA data was also obtained for the same period and domain. The IMSRA and TMPA data were at $0.25^{\circ} \times 0.25^{\circ}$ grid resolution. The GPI estimate was at $1^{\circ} \times 1^{\circ}$ intervals. This was interpolated to a $0.25^{\circ} \times 0.25^{\circ}$ grid resolution using a nearest neighbour technique. For additional validation with ground data, 22 raingauge stations were selected over the Indian region, and the 3 hourly point accumulations of rainfall from these stations was also used to validate the gridded rainfall derived from the GPI and IMSRA. These stations are uniformly spread throughout the country and are selected, based on the regular availability of their data (figure 1).

The Meteorological Evaluation Tools (MET) package (http://www.dtcenter.org/met/users/ index.php) is employed for evaluating the two algorithms over the monsoon season of 2010. Created by the WRF Developmental Testbed Center at the National Center for Atmospheric Research, the MET package is a highly-configurable, stateof-the-art suite of model verification tools. It was developed to verify the output from WRF model, but may be applied to any other gridded data source as well, that has a coherent spatial structure. Our objective for using MET software is, to incorporate a more standardized verification platform. For this specific project, we are especially interested in capitalizing on the objectoriented verification methodology that has been implemented in MET. The Method for Objectbased Diagnostic Evaluation (MODE; Davis et al. 2006a, 2006b; Brown et al. 2007) utility classifies 'objects' in gridded fields, calculates a wide variety of object attributes, and merges/pairs forecast objects with observed objects to determine the similarities and differences between the various objects. A major advantage of this methodology over earlier grid-based error computation methodologies is the avoidance of the 'double penalty'

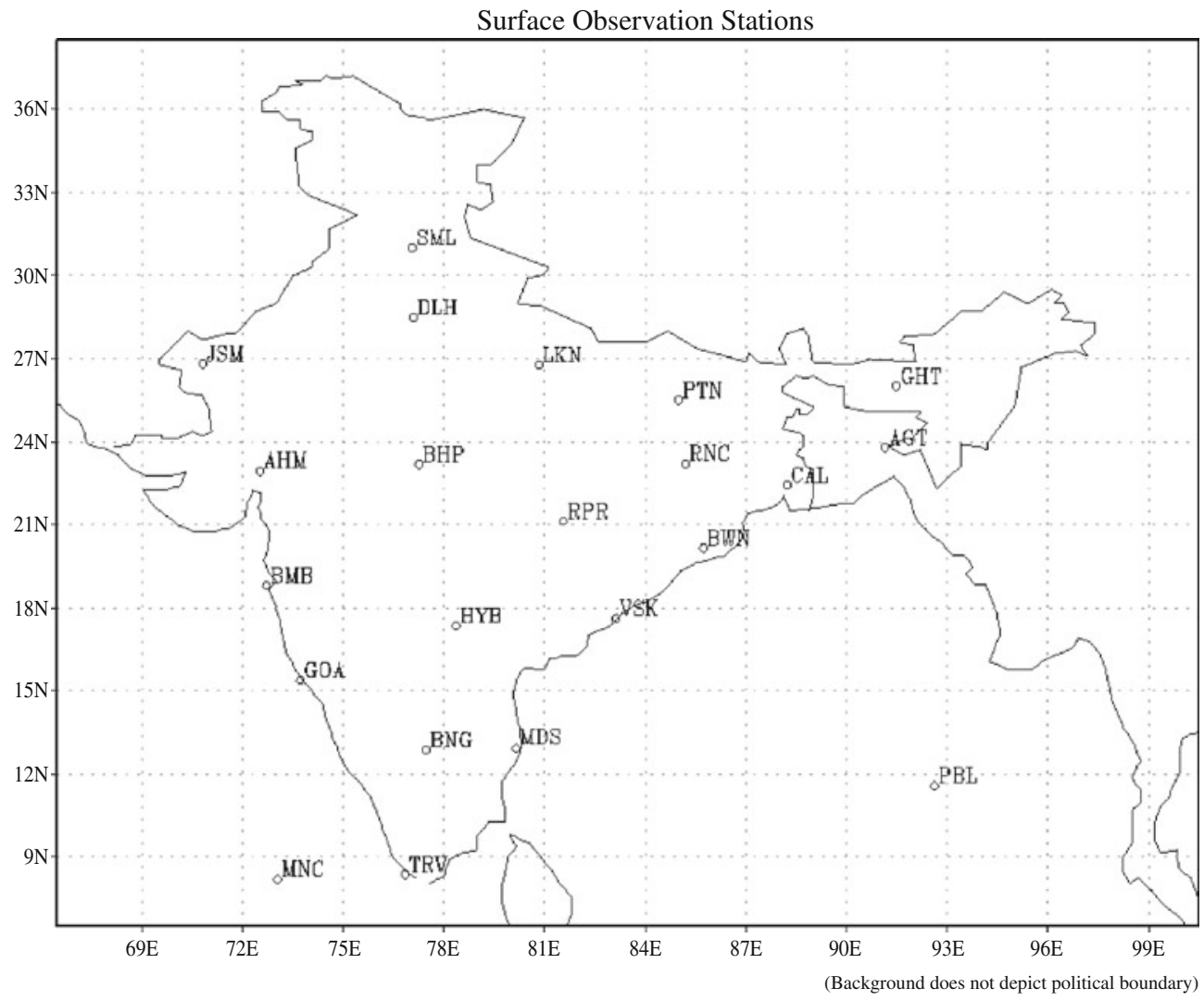

Figure 1. Raingauge stations of India Meteorological Department used for validation of the IMSRA and GPI rainfall estimates. 
problem in forecast verification. According to this, a forecast missed by even a small distance is effectively penalized twice by standard categorical verification scores: once for missing the event and a second time for producing a false alarm of the event elsewhere. The MODE software relies on user-specified parameters to identify similar features (such as precipitation elements) in forecasts and observations. The object-based verification metrics, available in MODE, are capable of diagnosing systematic biases. The datasets are compared in pairs, involving TMPA and GPI rainfall estimates in one set of comparisons, and TMPA and IMSRA estimates, in another set of comparisons. Histograms of various assessment parameters are created for the entire observation period of four months, to obtain a holistic view of the relative performance of the two algorithms for the entire period, rather than that for an individual case. Also, the histograms give a more complete assessment of the variation of the error parameters, which would not be possible, if a single average value was calculated for the entire dataset. This is then illustrated with case studies, to highlight the main features of the general result. The point-stat tool of the MET software is used to compare the point data of rainfall with the gridded rainfall estimates derived by the GPI and the IMSRA technique. In this case too, the histograms for the root mean square errors (RMSE) for the entire period are plotted to obtain a holistic view of the biases.

\section{Results and discussion}

\subsection{Validation for the entire period with respect to TMPA}

The evaluation statistics are derived independently for precipitation estimates from the two algorithms, IMSRA and GPI with respect to the TMPA rainfall estimates, available at 3 hourly intervals. The two sets of evaluation statistics for the entire dataset are then compared for their relative performance.

During the convolution process in the MODE software, depending on a threshold value set in the configuration file (in this case $0 \mathrm{~mm} / \mathrm{hr}$ ), individual objects are identified in the two fields under comparison. The ratio of the total number of objects in the GPI (IMSRA) field to the total number of objects in the TMPA field for a set of 3 hourly observations indicates, how well the MODE software is able to delineate objects in the two data fields being compared. The ratio of the respective areas of the delineated objects in the two fields -
GPI (IMSRA) and TMPA, indicates the total precipitation area in the two data fields. A histogram of this ratio is computed for all the object sets for the entire dataset, to indicate the distribution of the difference of the character of the objects in the two datasets - GPI (IMSRA) and TMPA. Figure 2( $\mathrm{a}$ and $\mathrm{b})$ gives the percentage frequency histograms of the two sets of data for the entire period. The figure indicates that the total number of objects that are detected in both the IMSRA and GPI precipitation fields are almost double the number of objects in the TMPA field. However, the area of the objects is much larger for the GPI field, indicating larger precipitation areas than the IMSRA data field as compared to the TMPA precipitation field.

When the matched precipitation objects in the two data fields - TMPA and GPI (IMSRA) do not overlap at all, at any precipitation threshold, traditional scores such as False Alarm ratio, Critical Success Index and Hanssen-Kuipers $(\mathrm{H}-\mathrm{K})$ are zero or less, indicating no (or negative) skill. Fortunately, MODE creates complex clusters of the simple objects that it identifies as a first step, and then matches objects in the two fields for calculating the standard statistics. Frequency bias is the ratio of the total number of grid points on an object in the GPI (IMSRA) gridded field to the total number of grid points for a matched object in the TMPA gridded data field. A perfect score of 1 , would indicate equal number of grid points in the matched objects in the respective fields. A score greater than one indicates that the objects in the GPI (IMSRA) field are bigger than the corresponding objects in the TMPA field and vice versa. Figure 2(c) displays the percentage frequency histograms of frequency bias in the GPI (IMSRA) dataset with respect to the TMPA field for the entire period. As may be observed, while both GPI and IMSRA overestimate the size of the precipitation field objects with respect to the TMPA observation field, the IMSRA field objects are closer in size to those of the TMPA field, as compared to the GPI field. Threat Score (Critical Success Index: CSI) is the ratio of the number of overlapping grid points in a pair of matching objects where rainfall occurred according to GPI (IMSRA) as well as TMPA to the total number of grid points of the matching objects. A value close to 1 indicates perfect overlap of the matched composite objects in the two fields being compared - TMPA and GPI (IMSRA). Figure 2(d) displays the percentage frequency histograms of the CSI values for the two datasets. Both datasets - GPI and IMSRA, are poorly collocated with the corresponding TRMM data field. This parameter is of course susceptible to navigational inaccuracies of the Kalpana-1 satellite and we expect this to appear as a systematic 


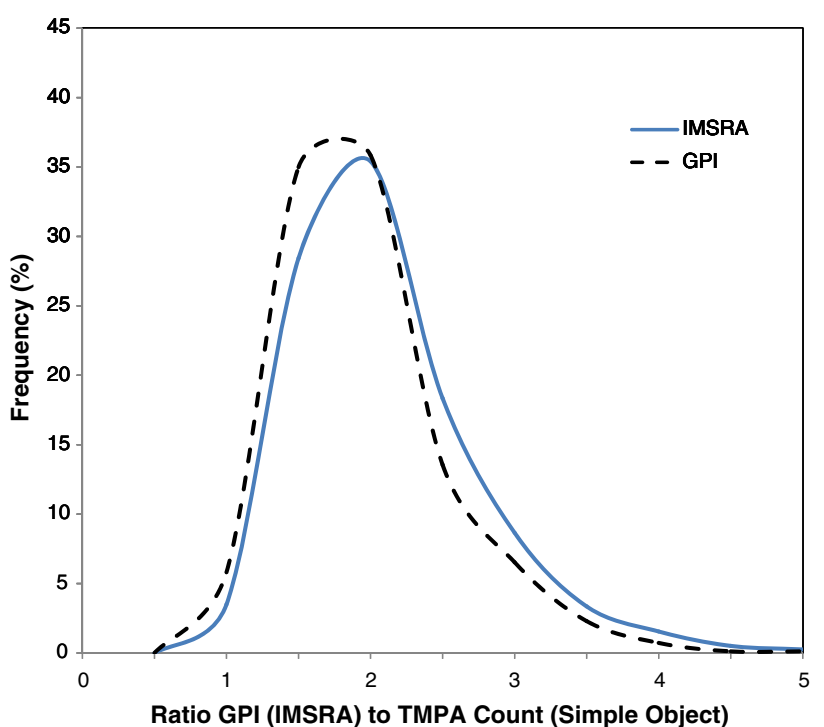

(a)

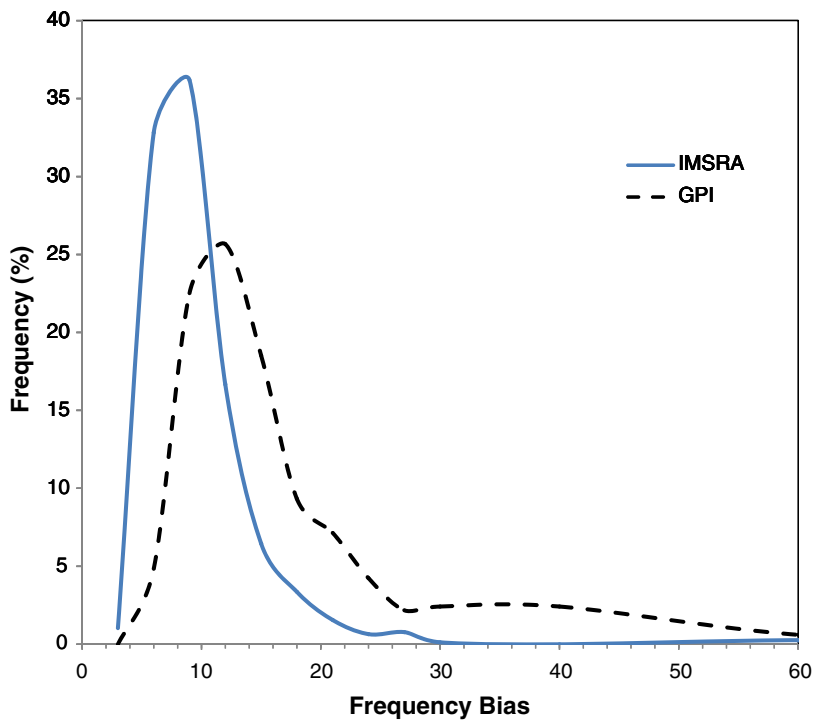

(c)

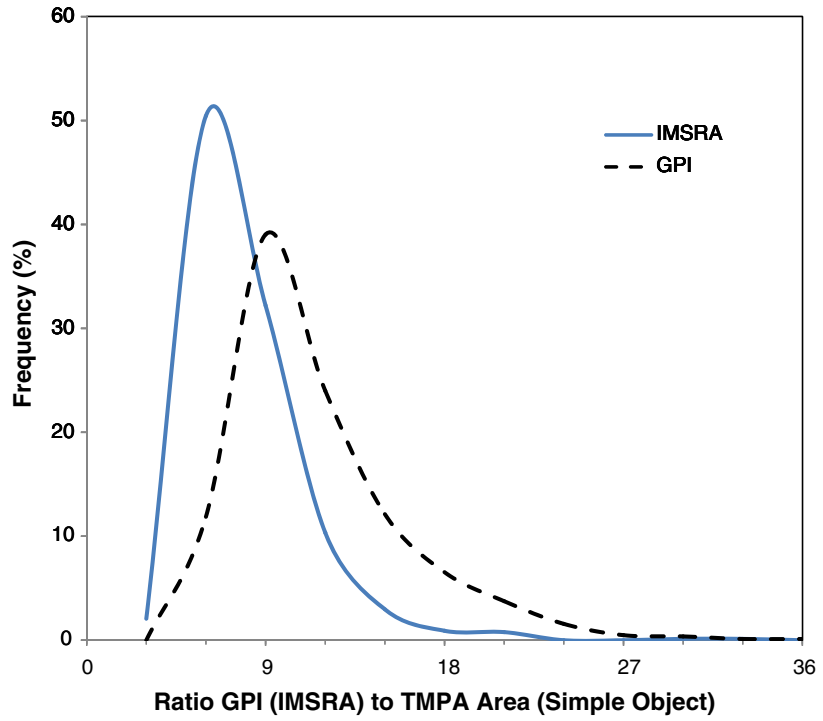

(b)

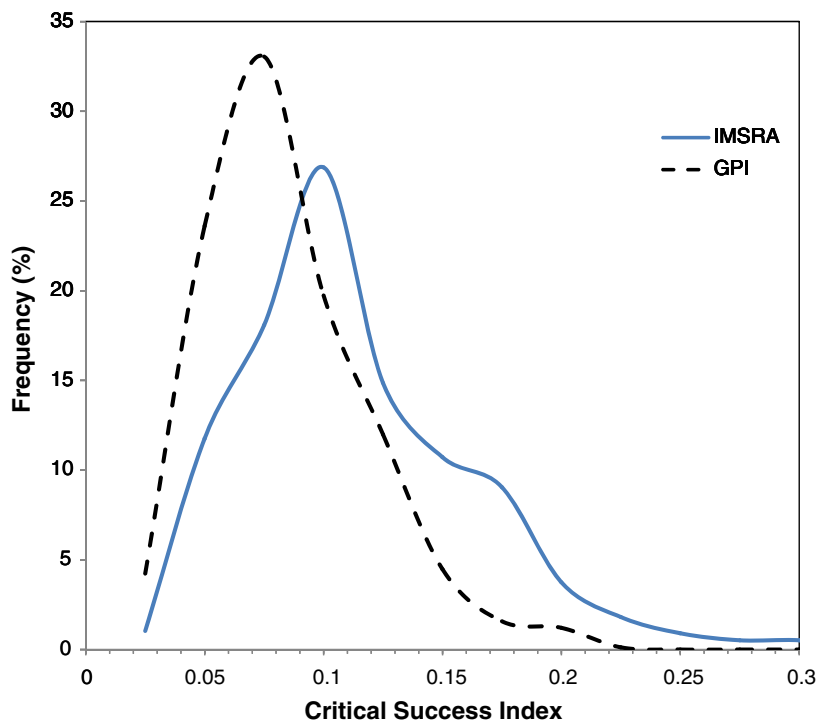

(d)

Figure 2. (a) Percentage frequency histogram of the ratio of the total number of GPI (broken line) and IMSRA (solid line) rainfall objects to TMPA rainfall objects. (b) Percentage frequency histogram of the ratio of the total area of GPI (broken line) and IMSRA (solid line) rainfall objects to TMPA rainfall objects. (c) Percentage frequency histogram of the frequency bias of GPI (broken line) and IMSRA (solid line) rainfall objects with respect to matched TMPA rainfall objects. (d) Percentage frequency histogram of the Critical Success Index of GPI (broken line) and IMSRA (solid line) rainfall objects with respect to matched TMPA rainfall objects. (e) Percentage frequency histogram of the distance of the centroids of the GPI (broken line) and IMSRA (solid line) fields from the matched TMPA rainfall objects. (f) Percentage frequency histogram of the ratio of the 50th percentile value of rainfall in of GPI (broken line) and IMSRA (solid line) rainfall objects with respect to matched TMPA rainfall objects. (g) Percentage frequency histogram of the ratio of the 90th percentile value of rainfall in of GPI (broken line) and IMSRA (solid line) rainfall objects with respect to matched TMPA rainfall objects.

error in both datasets - GPI and IMSRA. Despite the potential inaccuracies, IMSRA is marginally better (peaks at higher CSI values) than the GPI estimates, indicating closer correspondence in the location of the precipitating areas.

The errors in displacement and aspect ratio of the matched objects, arising out of the geometry of the identified objects in the two gridded fields also needs to be accounted for. These errors are especially difficult to discern with traditional verification methods. Knowledge of these errors could be useful for algorithm development and improvement, and could be informative for users of the precipitation estimates. The centroid distance between an object pair being compared, is one of the matching criteria for objects. The centroid is a kind of geometric center of an object, and can be calculated from first moments. It allows one to assign a single point location to what may be a large, extended object, and can account for the 


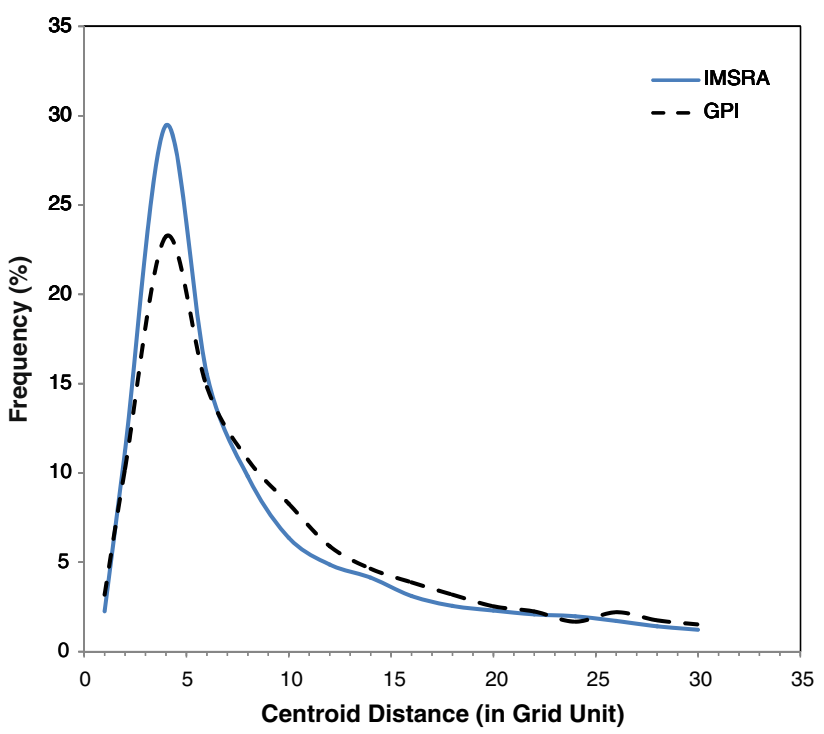

(e)

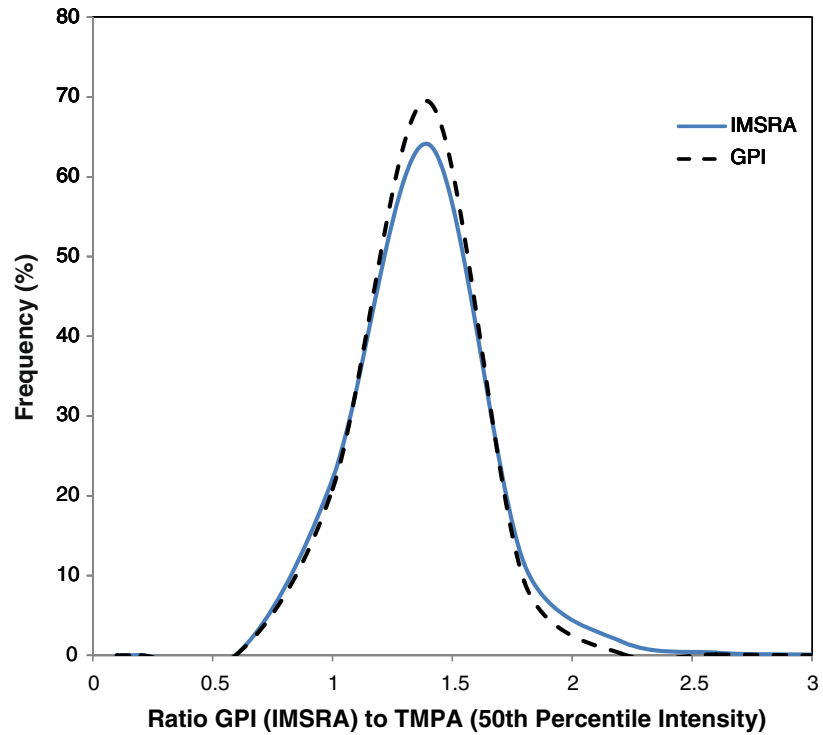

(f)

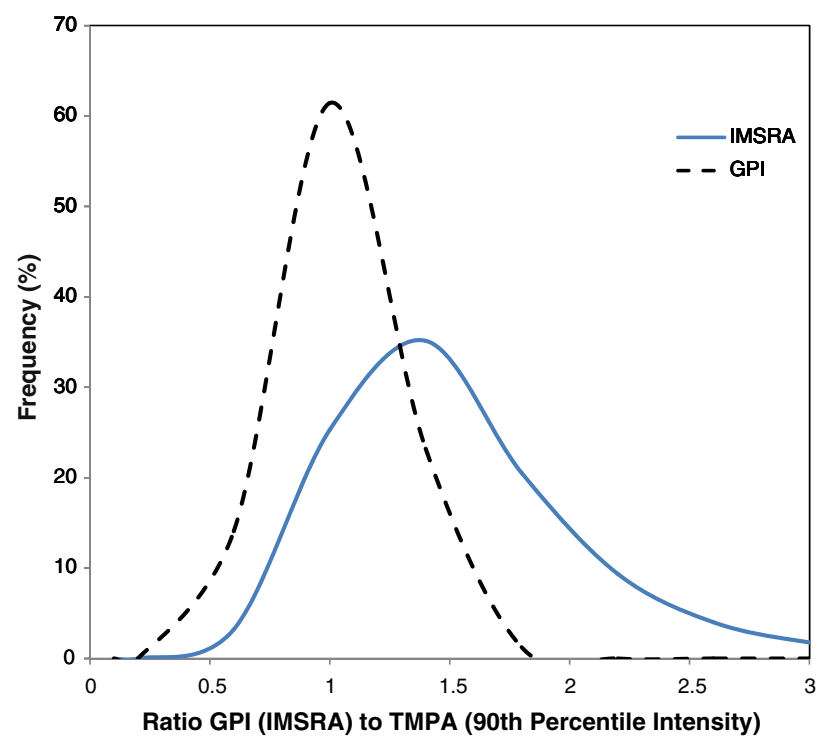

(g)

Figure 2. (Continued)

shape of an object. Figure 2(e) displays the centroid difference between the matched object pairs in the TMPA and GPI (IMSRA) data fields for the entire period of study. Though both datasets peak at small centroid distances (about 5 grid units), the curve is more peaked for the IMSRA data as compared to the GPI data, which is broader and flatter. This implies that in the case of IMSRA field, most object pair centroid distances are bunched round 5 grid units. A broader, flatter curve for GPI indicates more variation in centroid distances, pointing to greater displacement errors and shape differences with respect to the TMPA field.

In addition to the geometric aspect of the objects, dealt with so far in this study, one also needs to compare the intensity values in the objects matched. MODE has the ability to identify the 10th, 25th, 50th, 75th, and 90th percentiles of intensity of the data field within the identified object. The ratio of the values for a pair of matching objects in the GPI (IMSRA) and TMPA fields should be close to 1 to indicate similar assessment of rainfall intensity. The 50th percentile of intensity was selected for comparison, in order to highlight the average values within an object while the 90th percentile was selected to highlight the more intense values in the objects identified. Figure 2(f) displays the percentage histogram of the ratio of 50th percentile intensity of GPI (IMSRA) and TMPA matching object pairs for the entire period. As may be seen from the figure, the GPI (IMSRA) 
field objects overestimate the value of precipitation compared to the corresponding matched object in the TMPA field. The 90th percentile ratio in figure $2(\mathrm{~g})$ also shows a similar behaviour of the IMSRA field. However, the GPI value is close to 1 , indicating matching values in the TMPA and GPI fields. This indicates that, for the entire dataset, the average value of the data in both the GPI and IMSRA data fields is higher than that in the TMPA field. However, for the more severe rainfall areas (the top $10 \%$ of the area), the precipitation estimate by the GPI technique matches with the one that is derived by the TMPA technique, while the estimation by the IMSRA technique is generally higher.

\subsection{Case studies of validation with respect to TMPA}

The difference between the three fields is further illustrated by the following two case studies.

\subsubsection{August 2010 (0600 UTC)}

On 1 August, 2010, southwest monsoon was active over most parts of the country. It was mostly active at 0600 UTC over the Bay of Bengal and southeast Asia, and also the west coast of India off the Gujarat coast. While the geographical location of the 3-hour accumulated rainfall patches is almost identical in all the three images of figure 3(a), the IMSRA and GPI estimates (figure $3 \mathrm{a}(\mathrm{i})$ and (iii) respectively) at all the grid points, are generally higher than the values according to TMPA (figure $3 \mathrm{a}(\mathrm{ii})$ ). In fact the GPI estimate saturates over most of the area of the two rainfall patches (reaches the maximum value of $9 \mathrm{~mm}$ in 3 hours). However, the intense areas within the two main rainfall patches off the east and west coast of India (of the order of $15 \mathrm{~mm}$ in the TMPA estimates) are not at all captured by the GPI estimates. This is not so for the IMSRA rainfall estimates, which in fact assess the rainfall amount in the heavier rainfall patches to be higher (reaching up to $22 \mathrm{~mm}$ ) as compared to those observed in the TMPA field. The actual area of precipitation for the rainfall patches is also larger for IMSRA and GPI estimates, with respect to the TMPA estimates.

\subsubsection{September 2010 (1500 UTC)}

On 14 September, 2010, southwest monsoon was active over most parts of India and its neighbourhood. The 3 hourly rainfall from the GPI, TMPA and IMSRA fields all show heavy rainfall patches over the eastern peninsular India, Gangetic West Bengal and east-central India (figure 3b). While the location of the rainfall patches were similar in all the three estimates, both rainfall fields (GPI and IMSRA) provide higher estimates of rainfall for most of the patches in respect of the TMPA. In the TMPA data, there is a more intense patch over the central Indian peninsula, with rainfall of the order of $15 \mathrm{~mm}$ (figure $3 \mathrm{~b}$ (ii)). The heaviest rainfall in the GPI estimates of figure $3 \mathrm{~b}(\mathrm{i})$, saturates at about $9 \mathrm{~mm}$ over southeastern peninsula. This is in line with the maximum possible rainfall value for 3 hours, according to Arkin's technique. The rainfall is more intense over the central and east Indian peninsula in figure $3 \mathrm{~b}$ (iii) for IMSRA gridded rainfall, though the relative location of the rainfall patches is similar to figure $3 \mathrm{~b}(\mathrm{i})$ and (ii). Also in this case, within the main patch of the IMSRA rainfall, smaller patches with rainfall values of the order of $22 \mathrm{~mm}$ are visible. The other rainfall patches in the domain are also more intense than the other two data fields.

Both the above cases clearly validate the findings of the previous section 3.2.1, in the composite quantitative results from MODE software. These results also match the findings of Prakash et al. (2010), for the daily rainfall of 6 June 2008.

\subsection{Validation for the entire period with respect to raingauge data}

It may, however, be argued that these measurements with respect to TMPA, may be somewhat biased by any systematic errors in the TMPA methodology itself for rainfall estimation. It has been observed earlier that the TMPA has lower skill in correctly specifying moderate and light rain event amounts on short time intervals (Huffman et al. 2007). The TMPA estimates of rainfall amounts over the Indian region were also found to be most accurate over regions of moderate rainfall and mainly inaccurate in regions of sharp rainfall gradient (Nair et al. 2009). For daily rainfall estimates derived by a similar algorithm by Mishra et al. (2010) using Meteosat data, the results were encouraging, as compared to the TMPA rainfall estimates. Hence the underestimation of high rain events over smaller temporal and spatial scales by TMPA may be argued to have caused the observed overestimation by IMSRA. This may also have resulted in better matching of the TMPA rainfall rates for heavy rainfall episodes (the 90th percentile values) with the corresponding values obtained for GPI, which is capped by the Arkin algorithm to a maximum value of $3 \mathrm{~mm} / \mathrm{hr}$. To conclusively prove the same or otherwise, 3 hourly ground measurements of rainfall from 22 stations distributed uniformly all over India, were also compared with the gridded values of rainfall estimates by the GPI and IMSRA techniques. As mentioned 

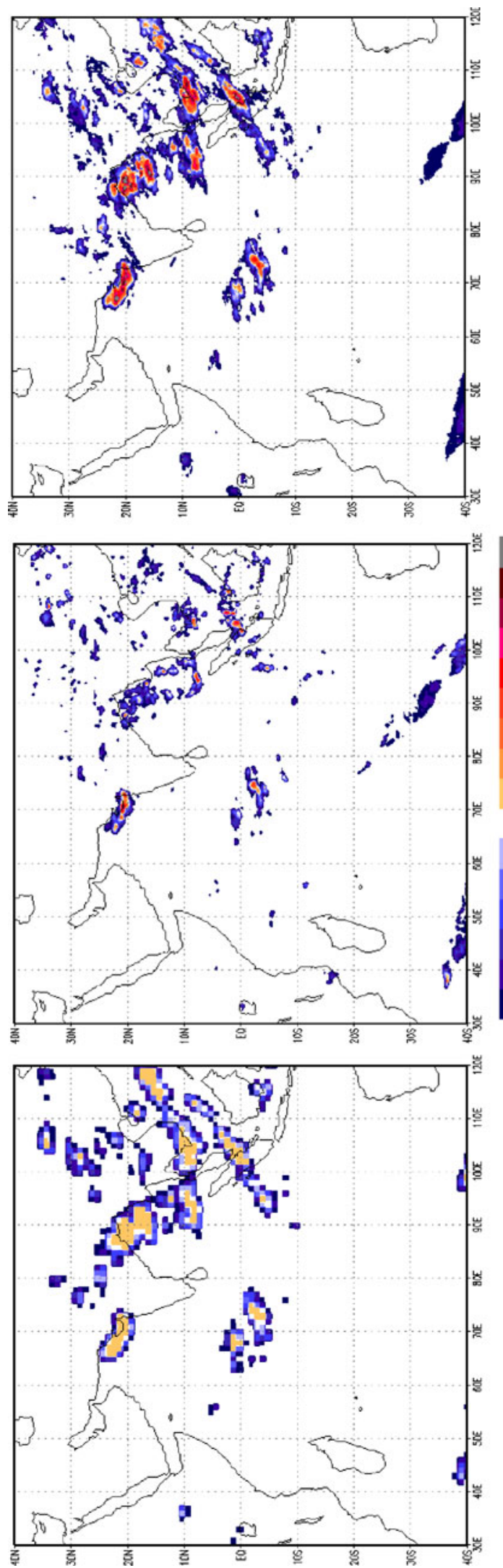
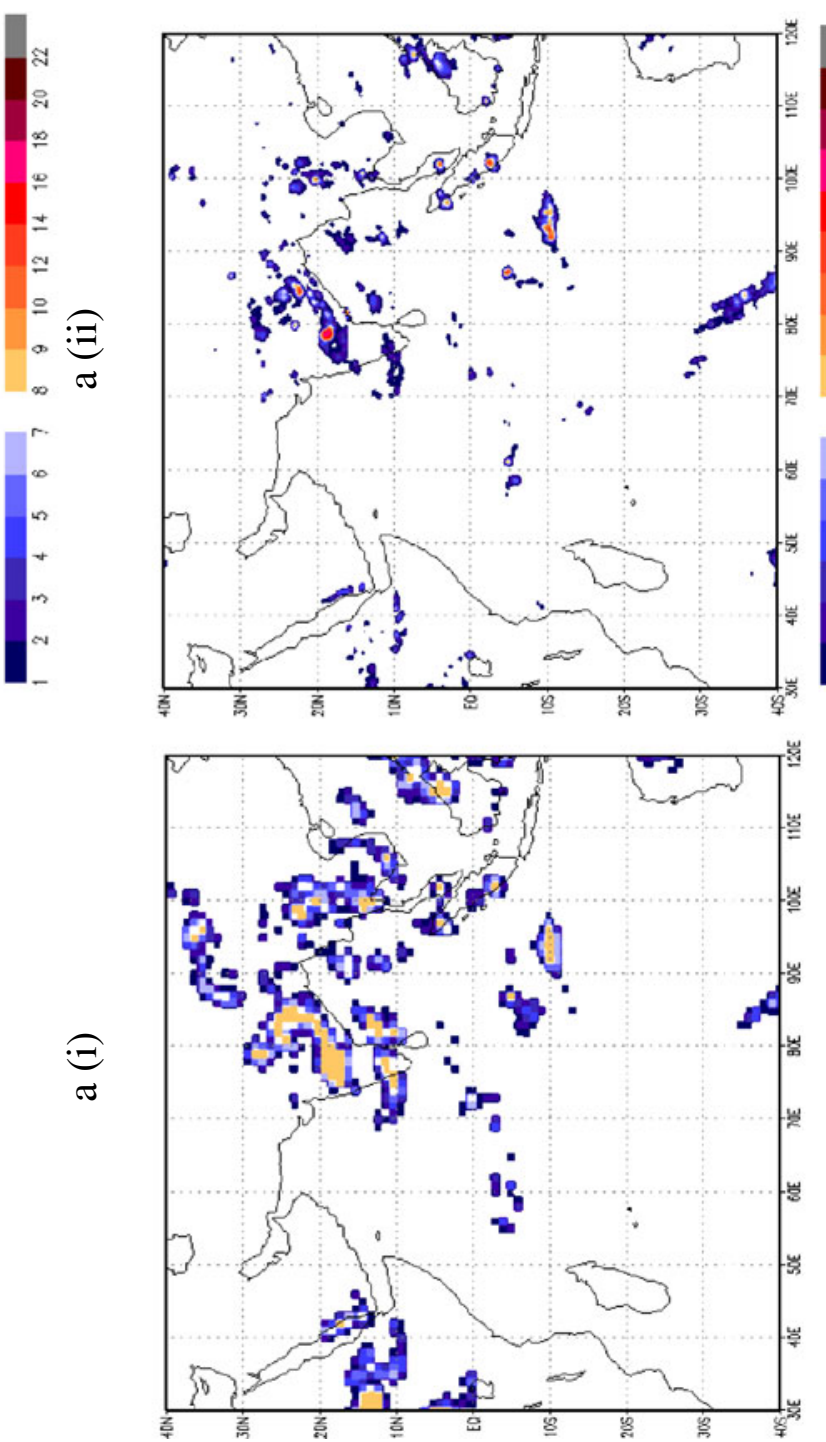
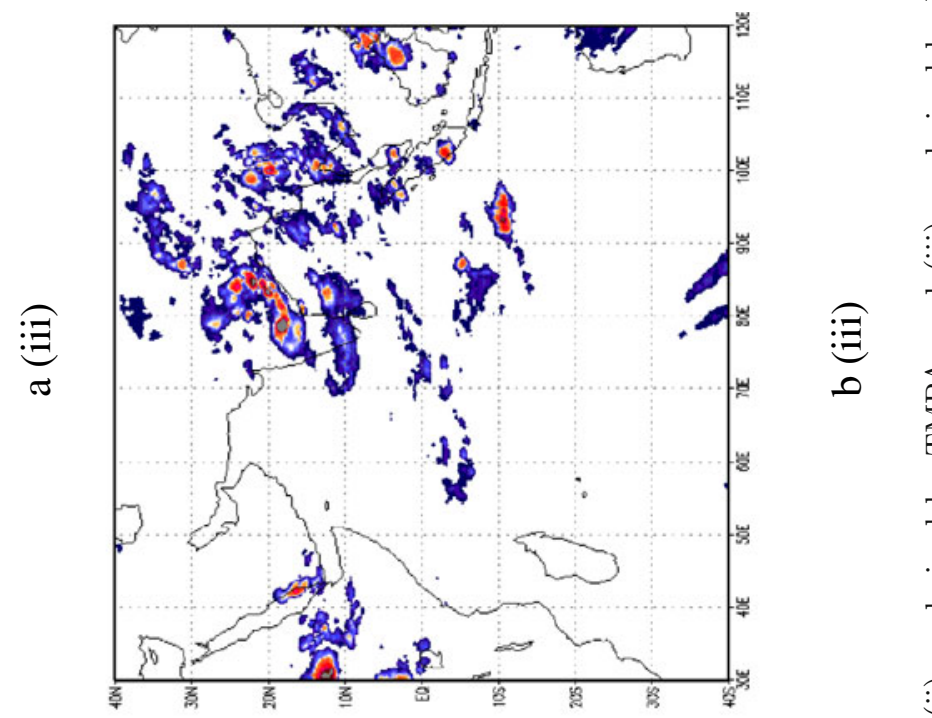

近

$\Xi$

年

ชิ

.

운

묵응

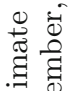

$\Theta \quad$ 苟

0 


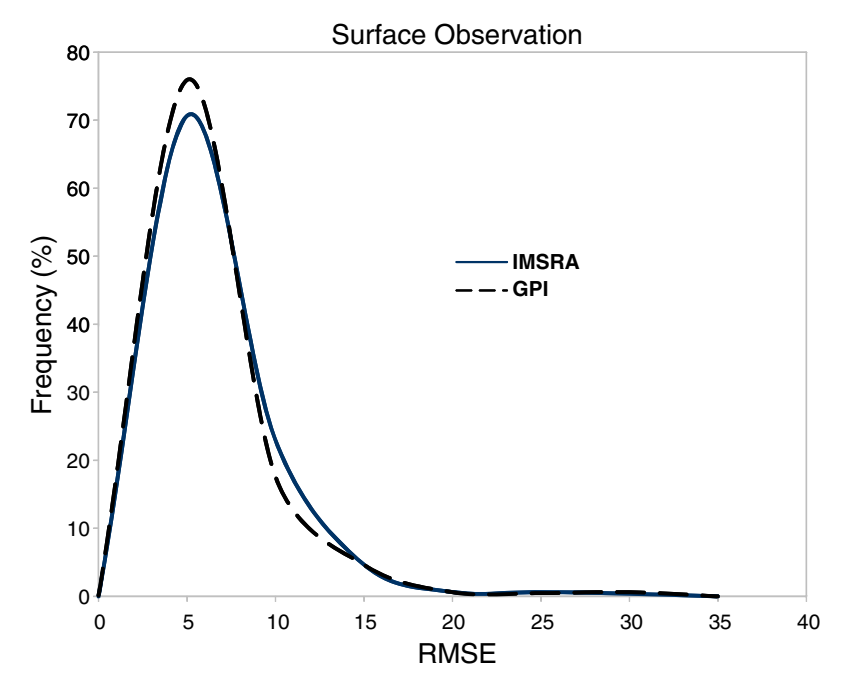

Figure 4. Histogram of root mean square error between raingauge and IMSRA (solid line) and between raingauge and GPI (dashed lines).

earlier, the Point-Stat software was used for this purpose. The histogram plot of the RMSE values for each 3 hourly rainfall estimate by both techniques, for all stations is shown in figure 4 . This shows a systematic error in the satellite measurements of rainfall (GPI and IMSRA), with respect to the point measurements of rainfall (peaking at RMSE of $5 \mathrm{~mm} / \mathrm{hr}$ ). However, the peak is sharper for GPI as compared to IMSRA, with the latter having more values at higher RMSE errors as compared to GPI. This indicates a slightly greater systematic error in IMSRA rainfall measurements as compared to GPI. Seen in conjunction with the results of sections 3.2.1 and 3.2.2, this indicates that the small but significant error in the top $10 \%$ of rainfall rate values in the rainfall patches measured by the IMSRA technique as compared to the TMPA estimates in the previous section, is real. This difference in estimation of extreme rainfall zones in the IMSRA dataset will be smoothed out when averaged over longer time scales - daily or monthly, since the duration of these episodes is less in an overall rainfall episode. But this is likely to be a serious issue for estimating short period rainfall, especially during non-monsoon season, when the rainfall spells are localized, intense and of short duration.

\section{Conclusions}

The IMSRA technique for rainfall estimation using data of the Kalpana-1 satellite has been developed to address the constraints of using the GPI estimates for short term rainfall estimation. This new technique uses the infra-red and water vapour channel data of Kalpana-1 satellite to classify rain-bearing clouds, and then derives a regression relation for surface rain rate using the IR brightness temperature and Tropical Rainfall Measuring Mission (TRMM)-Precipitation Radar (PR) surface rain rate. This is a quantitative verification study of the efficacy of the short period estimation of the IMSRA derived rainfall, with respect to the GPI derived rainfall as compared to the TMPA rainfall estimates.

The object classification technique of MODE is particularly useful for quantifying the errors of a discontinuous field such as precipitation. The results show that, in terms of almost all geometrical parameters, the rainfall objects in the IMSRA gridded rainfall data field better match the TMPA gridded rainfall field, as compared to the GPI estimates. The IMSRA measured areas of rainfall, show greater overlap with the corresponding rainfall areas of the TMPA estimates, as compared to the GPI estimates. The shapes of the rainfall objects are also more similar in the two data fields (IMSRA and TMPA) as compared to the GPI data field. The average intensity of the rainfall patches is more for both the IMSRA and GPI fields with respect to the TMPA estimation. However, the capping maximum value of $3 \mathrm{~mm} / \mathrm{hr}$ in the GPI estimation field according to Arkin's technique, keeps the 3 hourly maximum rainfall for the most intense patches to below $10 \mathrm{~mm} / \mathrm{hr}$. This is not so for the IMSRA rainfall. The extreme rainfall values are very high in the IMSRA estimation. Similar results are also observed, in comparisons of the two rainfall estimates with raingauge data, which further validate the above findings. This difference is small, and will be smoothed out when accumulated over longer periods (daily or monthly), but is likely to create serious problems when used for short period (3 hourly) rainfall estimation for very heavy rainfall episodes.

\section{Acknowledgements}

The authors are grateful to the Director General of Meteorology, India Meteorological Department, for constant encouragement during the course of this study. We are grateful to a large number of officers, namely Dr V Rajeswara Rao and other staff members at IMD, New Delhi for providing the IMSRA and GPI estimates of rainfall.

\section{References}

Adler R F, Huffman G J, Chang A, Ferraro R, Xie P P, Janowiak J, Rudolf B, Schneider U, Curtis S, Bolvin D, Gruber A, Susskind J, Arkin P and Nelkin E 2003 The version-2 Global Precipitation Climatology Project (GPCP) monthly precipitation analysis (1979-Present); J. Hydrometeorol. 4 1147-1167. 
Arkin P A 1979 The relationship between fractional coverage of high cloud and rainfall accumulations during GATE over the B-scale array; Mon. Weather Rev. 107 1382-1387.

Arkin P A and Ardanuy P E 1989 Estimating climaticscale precipitation from space: A review; J. Climate $\mathbf{2}$ 1229-1238.

Arkin P A, Krishna Rao A V R and Kelkar R R 1989 Large scale precipitation and outgoing longwave radiation from INSAT-1B during the 1986 south west monsoon season; J. Climate 2 619-628.

Brown B G, Bullock R, Halley Gotway J, Ahijevych D, Davis C, Gilleland E and Holland L 2007 Application of the MODE object-based verification tool for the evaluation of model precipitation fields; $A M S$ 22nd Conference on Weather Analysis and Forecasting and 18th Conference on Numerical Weather Prediction, 25-29 June, Park City, Utah, American Meteorological Society (Boston), available at http://ams.confex.com/ams/ pdfpapers/124856.pdf.

Chokngamwong R and Chiu L 2007 Thailand daily rainfall and comparison with TRMM products; J. Hydrometeorol. 9(2) 256-266.

Davis C A, Brown B G and Bullock R G 2006a Object-based verification of precipitation forecasts, Part I: Methodology and application to mesoscale rain areas; Mon. Weather Rev. 134 1772-1784.

Davis C A, Brown B G and Bullock R G 2006b Object-based verification of precipitation forecasts, Part II: Application to convective rain systems; Mon. Weather Rev. 134 1785-1795.

Dinku T, Ceccato P, Grover-Kopec E, Lemma M, Connor S J and Ropelewski C F 2007 Validation of satellite rainfall products over East Africa's complex topography; Int. J. Remote Sens. 28(7) 1503-1526.

Durai V R, Roy Bhowmik S K and Mukhopadhyay B 2010 Evaluation of Indian summer monsoon rainfall features using TRMM and Kalpana-1 satellite derived precipitation and rain gauge observations; Mausam 61(3) 317-336.

Feidas H 2010 Validation of satellite rainfall products over Greece; Theor. Appl. Climatol. 99 193-216.

Gairola R M and Krishnamurti T N 1992 Rain rates based on SSM/I, OLR and rainguage data sets; Meteorol. Atmos. Phys. 50(4) 165-174.

Gairola R M, Mishra A, Prakash S and Mahesh C 2010 Development of INSAT multi-spectral rainfall algorithm (IMSRA) for monitoring rainfall events over India using Kalpana-IR and TRMM-precipitation radar observations, Scientific Report, SAC/EPSA/AOSG/INSAT/SR$39 / 2010$.

Han W S, Burian S J and Shepherd J M 2011 Assessment of satellite-based rainfall estimates in urban areas in different geographic and climatic regions; Nat. Hazards 56(3) $733-747$.

Huffman G J, Bolvin D T, Nelkin E J, Wolff D B, Adler R F, Gu G, Hong Y, Bowman K P and Stocker E F 2007 The TRMM multisatellite precipitation analysis (TMPA): Quasi-global, multiyear, combined-sensor precipitation estimates at fine scales; J. Hydrometeorol. 8 38-55.

Islam N and Uyeda H 2005 Comparison of TRMM 3B42 products with surface rainfall over Bangladesh; In: Proceedings of Geoscience and Remote Sensing Symposium, IGARSS '05, 2005, IEEE International 6 4112-4115.

Kummerow C, Barnes W, Kozu T, Shiue J and Simpson J 1998 The status of the Tropical Rainfall Measuring
Mission (TRMM) sensor package; J. Atmos. Oceanic Technol. 15 809-817.

Krajewski W F 1993 Global estimation of rainfall: Certain methodological issues; In: World at Risk: Global Climate Change and Natural Hazards (ed.) Bras R, Proc. Conf. American Institute of Physics 277 180-192.

Li Li, Yang Hong, Jiahu Wang, Adler R F, Policelli F S, Habib S, Irwn D, Korme T and Okello L 2008 Evaluation of the real-time TRMM-based multi-satellite precipitation analysis for an operational flood prediction system in Nzoia Basin, Lake Victoria, Africa; Nat. Hazards 50(1) 109-123.

Mishra A, Gairola R M, Varma A K and Agarwal V K 2010 Remote sensing of precipitation over Indian land and oceanic regions by synergistic use of multi-satellite sensors; J. Geophys. Res. 115 D08106, doi: 10.1029/ 2009JD012157.

Nair S, Srinivasan G and Nemani R 2009 Evaluation of multisatellite TRMM derived rainfall estimates over a western state of India; J. Meteorol. Soc. Japan 87(6) 927-939.

Prakash S, Mahesh C, Gairola R M and Pal P K 2010 Estimation of Indian summer monsoon rainfall using Kalpana-1 VHRR data and its validation using rain gauge and GPCP data; Meteorol. Atmos. Phys. 110(1-2) $45-57$.

Prakash S, Mahesh C and Gairola R M 2011 Large-scale precipitation estimation using Kalpana-1 IR measurements and its validation using GPCP and GPCC data; Theor. Appl. Climatol. 106(3-4) 283-293, doi: 10.1007/ s00704-011-0435-7.

Rahman H and Sengupta D 2007 Preliminary comparison of daily rainfall from satellites and Indian gauge data, CAOS Technical Report No. 2007AS1, Centre for Atmospheric and Oceanic Sciences, Indian Institute of Science, Bangalore.

Rahman S H, Sengupta D and Ravichandran M 2009 Variability of Indian summer monsoon rainfall in daily data from gauge and satellite; J. Geophys. Res. 114 D17113, doi: 10.1029/2008JD011694.

Richards F and Arkin P A 1981 On the relationship between satellite-observed cloud cover and precipitation; Mon. Weather Rev. 109 1081-1093.

Roca R, Viollier M, Picon L and Desbois M 2002 A multisatellite analysis of deep convection and its moist environment over the Indian Ocean during the winter monsoon; J. Geophys. Res. 107(INX2) 1-25.

Su F, Hong Y and Lettenmaier D P 2008 Evaluation of TRMM multisatellite precipitation analysis (TMPA) and its utility in hydrologic prediction in the La Plata Basin; J. Hydrometeorol. 9 622-664.

Todd M C, Kidd C, Kniveton D and Bellerby T J 2001 A combined satellite infrared and passive microwave technique for estimation of small-scale rainfall; J. Atmos. Oceanic. Technol. 18 742-755.

Villarini G 2010 Evaluation of the research-version TMPA rainfall estimate at its finest spatial and temporal scales over the Rome metropolitan area; J. Appl. Meteorol. Climatol. 49(12) 2591-2602.

Xie P and Arkin P A 1995 An intercomparison of gauge observations and satellite estimates of monthly precipitation; J. Appl. Meteorol. 34 1143-1160.

Yatagai A, Arakawa O, Kamiguchi K, Kawamoto H, Nodzu M I and Hamada A 2009 A 44-year daily gridded precipitation dataset for Asia based on a dense network of rain gauges; SOLA 5 137-140, doi: 10.2151/sola.2009-035. 